\title{
Participação popular e política habitacional em Belo Horizonte/MG
}

\author{
Davidson Afonso de Ramos ${ }^{1}$
}

\section{Resumo}

O presente artigo se propõe a analisar qual a relação que podemos estabelecer entre a participação popular e as políticas públicas habitacionais no município de Belo Horizonte. A perspectiva analítica que conduz o estudo é de que é absolutamente necessária a constituição de uma burocracia técnica para exercer o importante papel de racionalização política, capaz de se impor como mediadora no jogo dos interesses particulares. Todavia, essa burocracia tem de ser permeável às demandas da sociedade, caso contrário se fecharia em procedimentos ineficientes e pouco afeitos ao Estado Democrático de Direito. O elemento chave para a eficiência da ação estatal seria o equilíbrio entre autonomia e parceria.

Em função do excludente processo de urbanização que se observou no Brasil, a questão da moradia se tornou um dos principais pontos da agenda pública nacional. De modo que, a política habitacional se configura como um excelente objeto de estudo para a análise das relações entre Estado e sociedade. Isso por que, além de ser uma demanda universal, a natureza do bem produzido, a moradia, tem características que motivam a participação popular. Nesse sentido, o caso da Política habitacional de Belo Horizonte deixa muito evidente os conflitos e contradições de um experimento participativo.

Palavras-Chave: Participação popular, políticas Públicas, política habitacional, sociedade civil, burocracia pública, Estado e sociedade.

\footnotetext{
${ }^{1}$ Doutor em Sociologia - UFMG, Mestre em Ciência Política - UFMG, Bacharel em Ciências Sociais - UFMG, Professor Adjunto A de Ciência Política, Políticas Educacionais - UFVJM, Universidade Federal dos Vales do Jequitinhonha e Mucuri - UFVJM - Faculdade Interdisciplinar em Humanidades- FIH. Rodovia MGT 367- km 583, no 5000 - Alto da Jacuba / CEP: 39100-000, Diamantina - MG / Tel: (38) 3532-1200 davidson.afonso@ig.com.br
}

Latitude, Vol. 9, no 1, pp. 29-55, 2015

DOI: https://doi.org/10.28998/2179-5428.20150103 
Participação popular e política habitacional em Belo Horizonte/MG

\begin{abstract}
This article aims to analyze what relationship can be established between popular participation and public housing policies in the city of Belo Horizonte. The analytical perspective that leads the study is that it is absolutely necessary to set up a technical bureaucracy to exercise significant political rationalization role, able to impose itself as a mediator in the game of particular interests. However, this bureaucracy has to be permeable to the demands of society, otherwise would close in inefficient procedures and little accustomed to the democratic rule of law. The key element for State action efficiency would be the balance between autonomy and partnership. Due to the exclusionary process of urbanization has been observed in Brazil, the issue of housing has become one of the main points of the national public agenda. So that housing policy is configured as an excellent object of study for the analysis of relations between state and society. This is because, besides being a universal demand, the type of goods produced, housing, has features that motivate public participation. In this sense, the case of housing policy Belo Horizonte leaves very obvious conflicts and contradictions of a participatory experiment.
\end{abstract}

Keywords: Popular participation, public policy, housing policy, civil society, public bureaucracy, state and society.

\title{
Introdução
}

Em termos institucionais oficiais, a política habitacional em Belo Horizonte parte do princípio de que a racionalidade técnica pode e deve ser complementada pela participação popular. Todavia, aparatos participativos se deparam com um grande problema: a participação popular é muito incipiente. $\mathrm{O}$ maior desafio encontrado no trabalho de mobilização e capacitação social é o caráter volátil da participação, muitas vezes motivada por interesses particulares imediatistas, que uma vez atendidos, ou não, deixam de ter poder catalisador.

Outra grande dificuldade do trabalho social é a compatibilização dos anseios da comunidade com as possibilidades técnicas, com a viabilidade orçamentária e com o escopo das políticas públicas existentes. 
Em outras palavras, aparatos participativos têm o grande desafio de superar a oposição entre a visão da equipe técnica burocrática e a vontade popular, evitando assim o insulamento burocrático ${ }^{2}$.

Não podemos deixar de considerar o fato de que o estado moderno é o resultado de um contínuo processo de racionalização. Esse processo deu ao estado burocrático moderno a capacidade, e em alguns casos a obrigação, de superar a lógica individualista que muitas vezes motiva a participação social.

Um estado profissionalizado, formado por técnicos aprovados em concursos públicos, tenderia a desenvolver certo insulamento, relacionando-se com o mercado e a sociedade de forma autônoma. A tecnocracia do aparato estatal geralmente gostaria de preservar-se da pressão dos grupos de interesse. Dessa forma, estamos diante de alguns paradoxos:

1. Um aparato estatal profissionalizado, que tende ao insulamento, sendo obrigado a conviver e incentivar a participação popular.

2. Uma estrutura legal que pressupõe uma ampla participação popular e uma sociedade civil com baixo estoque de capital social.

Para melhor compreender o objeto de pesquisa proposto é preciso fazer um pequeno histórico do processo de urbanização brasileiro para em seguida discutir a participação nas políticas públicas e o caso específico de Belo Horizonte.

\section{O Processo de Urbanização e a Questão Habitacional}

O processo brasileiro de urbanização revela uma crescente associação com o processo de pobreza, cujo locus passa a ser a cidade, sobretudo a grande cidade. A cidade torna-se criadora e concentradora de pobreza, com capacidade também de atrair e manter gente pobre, ainda que muitas vezes em condições subumanas.

Segundo Milton Santos (1996), o processo de urbanização do Brasil pode ser dividido em algumas etapas:

1. No primeiro momento, que durou muitos séculos, o Brasil urbano era um grande arquipélago formado por subespaços que evoluíram

2 De acordo com Neves e Helal (2007), insulamento burocrático significa o distanciamento entre o Estado Burocrático moderno e a sociedade. 
Participação popular e política habitacional em Belo Horizonte/MG

segundo lógicas próprias, ditadas em grande parte por suas relações com o mundo exterior. Esses subespaços tinham entre si escassa relação, muito em função das dificuldades de comunicação. As cidades teriam uma zona de influência limitada.

2. Esse quadro é relativamente quebrado a partir da produção do café quando o estado de São Paulo torna-se polo dinâmico de uma vasta área. A integração territorial limita-se ao Sudeste e ao Sul.

3. Uma terceira fase foi inaugurada com o processo de industrialização das décadas de 1940 e 1950, quando o mercado nacional único se constitui. A industrialização ativou o processo de urbanização na medida em que formou um mercado nacional, expandiu o consumo, criou a necessidade de integrar o território e proporcionou o crescimento demográfico das cidades. O "Milagre Econômico" da década de 1970 intensifica ainda mais o fenômeno da metropolização.

A urbanização se generalizou no território nacional em função do processo de industrialização e da evolução dos meios técnico-científicos (meios de comunicação, de transporte, etc.), que viabilizaram a construção de espaços urbanos articulados.

Importante salientar que dentro do pensamento de Milton Santos (1996), os conceitos de industrialização e urbanização estão intimamente ligados, uma vez que o primeiro não se resume à simples criação de atividades industriais. $\mathrm{O}$ autor entende a industrialização como processo social abrangente que inclui: a formação de um mercado interno, a integração dos espaços, a expansão do consumo, a terceirização e o próprio processo de urbanização.

Todo esse processo de concentração da população nas grandes cidades, que começou na década de 1940, levou a uma explosão da demanda por habitações urbanas. Todavia, historicamente, a aquisição de uma moradia regular no mercado imobiliário formal sempre foi um sonho muito distante da realidade das famílias de baixa renda ${ }^{3}$.

Como bem observou a pesquisadora Mônica Maria Cadaval Bedê (2006), as famílias de baixa renda, que se veem impossibilitadas de solucionar o problema da moradia no âmbito do mercado imobiliário convencional, lançam mão de estratégias alternativas, tais como: aquisição de terrenos irregulares ou ocupações (ambas muitas vezes em áreas de

${ }^{3}$ Ver CARNEIRO et.al. (2010) e CARNEIRO; SOUZA, 2007. 
risco), autoconstrução, moradias improvisadas e coabitação de famílias. De acordo com Bedê:

...a maior parte das estratégias citadas resulta na formação de assentamentos habitacionais precários, que geralmente concentram problemas relativos a insalubridade, situações de risco geológicogeotécnico, condições inadequadas de acessibilidade e irregularidades urbanísticas. Os assentamentos habitacionais precários funcionam como focos de geração de processos de degradação ambiental e de violência que afetam não só seus moradores mas a população da cidade como um todo (BEDÊ, 2006, p.18).

As cidades brasileiras caracterizam-se pela profunda desigualdade social e pela total ausência de planejamento urbano, que acabou por gerar inúmeros assentamentos precários e um déficit habitacional gigantesco.

A falta de alternativas habitacionais, gerada pelo intenso processo de urbanização, baixa renda das famílias, apropriação especulativa das terras urbanizadas e inadequação das políticas de habitação, levou um contingente significativo da população a viver em assentamentos precários e informais.

Esses assentamentos precários se caracterizam pela informalidade na posse da terra, ausência ou insuficiência de infraestrutura, irregularidade no processo de ordenamento urbano, falta de acesso a serviços públicos, moradias com graves problemas estruturais e/ou situadas em áreas de risco. Estes dois últimos problemas ocorreram em decorrência direta da autoconstrução de moradias sem apoio técnico e institucional.

A cidade informal cresce a taxas muito superiores às da cidade formal, evidenciando a incapacidade do mercado e do setor público de viabilizarem alternativas mais adequadas. Loteamentos irregulares e ocupações espontâneas são abertos em áreas periféricas ou com restrição à urbanização (como áreas de risco e de proteção ambiental), dando origem às favelas, vilas, alagados, palafitas, entre outras modalidades precárias de moradia. 
Participação popular e política habitacional em Belo Horizonte/MG

Esse modelo, baseado no trinômio assentamento precário, autoconstrução e moradia própria, que caracterizou o forte processo de urbanização da segunda metade do século $X X$, continua presente em todas as regiões do país nos dias de hoje.

Sendo assim, as políticas públicas de habitação popular são centrais para a construção de um país mais justo, tendo impactos importantes em outras áreas como a da saúde, por exemplo.

\section{Participação Social e a Questão Habitacional no Brasil}

Historicamente, poderíamos dizer que o Brasil é um país com baixa propensão associativa em comparação com os Estados Unidos da América, essa constatação é corroborada pela leitura de Aléxis de Toqueville, Vitor Nunes Leal, e Roberto da Mata respectivamente nas seguintes obras: "A Democracia na América", "Coronelismo, Enxada e Voto" e "A casa e a Rua".

O processo de formação do Estado Nacional Brasileiro esteve muito ligado às relações verticalizadas, marcada pelo patriarcalismo, pelo clientelismo e pelo mandonismo local. No primeiro momento democrático da história brasileira (1946-1964) a pouca literatura existente aponta para um reduzido número de associações civis. $\mathrm{O}$ aparato estatal brasileiro sempre foi fortemente intervencionista tanto no campo econômico quanto no campo societário.

Foi apenas durante o processo de redemocratização, mas especificamente a partir da década de 1970, que se pôde observar um real crescimento do associativismo civil com uma característica mais autônoma e democrática. Começa-se a estabelecer a noção de demarcação entre sociedade civil e Estado e observa-se um crescimento expressivo das associações civis, principalmente nas capitais da região sudeste ${ }^{4}$.

Em um período muito curto, do início da redemocratização até os anos 2000, partiu-se de uma tradição associativa inexistente para um cenário em que a sociedade civil tem um papel fundamental nas políticas públicas. Esse crescimento tem como marco histórico a promulgação da Constituição Federal de 1988, que abriu a possibilidade institucional de

${ }^{4}$ Ver Leonardo Avritzer (2000) no texto "Sociedade Civil e Participação Social no Brasil". 
participação da sociedade civil e descentralizou as políticas. Essas duas mudanças são complementares na medida em que a descentralização, por um lado, fortaleceu os municípios em termos financeiros e institucionais, e por outro, deu condições reais para a participação popular. No entanto, desenvolver um desenho participativo no âmbito municipal é muito mais simples que fazê-lo nacionalmente.

O processo de redemocratização gerou uma legislação participativa bastante ampla no país. Existem inúmeras instâncias de participação popular, comissões e conselhos de composição mista e paritária (poder público, sociedade civil e em alguns casos o setor privado) que exercem um papel fundamental na implementação e acompanhamento de políticas públicas no Brasil. Do ponto de vista da engenharia institucional, o Estado brasileiro é formalmente muito permeável à participação popular.

Leonardo Avritzer aponta a

...presença na cena política no Brasil de uma sociedade civil que se organizou autonomamente em relação ao Estado no final dos anos 1970, que reinvindicou parceria nas políticas públicas nos anos 1980 e que expandiu fortemente a sua presença nessas áreas nos anos 1990. No entanto, essa sociedade civil reproduz desigualdades e heterogeneidades próprias da sociedade brasileira. Cabe ao Estado, em parceria com essa sociedade civil, oferecer incentivos que possam tornar a sociedade civil brasileira mais homogênea no que diz respeito a sua presença na sociedade brasileira (AVRITZER, 2000, p. 33).

No caso específico da política habitacional e urbana, a gênese do movimento popular de luta por moradia está muito ligada à atuação da Igreja Católica. Segundo Ana Maria Doimo, “desde o final dos anos 1960 a Igreja já vinha investindo na organização de moradores em torno da moradia" (DOIMO, 1995, P. 101).

Com esse intenso apoio da Igreja, o movimento sobreviveu durante o período da ditadura militar e manteve-se forte e atuante durante o processo de redemocratização da década de 1980, entrando nos anos 1990 
Participação popular e política habitacional em Belo Horizonte/MG

com muito fôlego, buscando uma maior articulação com outras organizações da sociedade civil, tais como universidade e sindicatos. De acordo com Ana Doimo:

Em março de 1991, depois de 16 meses de preparação e de consultas nas paróquias e comunidades, a Assembleia Arquidiocesana de São Paulo, que reuniu 500 delegados - padres, freiras e leigos - aprova a moradia como prioridade número 1 para a atuação da Igreja. E, no ano de 1993, a CNBB definiu o problema da moradia como tema da Campanha da Fraternidade. (DOIMO, 1995, P. 105).

Também entre a década de 80 e início de 90 surgem os principais movimentos nacionais de luta por moradia:

> União Nacional por Moradia Popular (UNMP). A UNMP iniciou sua articulação em 1989 e consolidou-se a partir do processo de coletas de assinaturas para o primeiro Projeto de Lei de Iniciativa Popular que criou o Sistema, o Fundo e o Conselho Nacional por Moradia Popular no Brasil (Lei 11.124/05) $)^{5}$.

> Movimento Nacional de Luta por Moradia (MNLM). “O MNLM foi criado em 1990, a partir do I Encontro Nacional dos Movimentos de Moradia. Materializou-se depois das grandes ocupações de áreas e conjuntos habitacionais nos centros urbanos, deflagradas principalmente na década de 80" (FERREIRA, 2012, P. 4).

Confederação Nacional das Associações de Moradores (CONAM). A CONAM foi fundada no dia 17 de janeiro de 1982 e tem como papel organizar as federações estaduais, uniões municipais e associações comunitárias, entidades de bairro e similares ${ }^{6}$.

${ }^{5}$ Mais informações ver site da entidade: http://www.unmp.org.br/.

${ }^{6}$ Mais informações ver site da entidade: http://www.conam.org.br/. 
$>$ Central dos Movimentos Populares (CMP). A CMP teve origem em 1980, quando foi constituída a Articulação Nacional dos Movimentos Populares e Sindicais (ANAMPOS). No final da década de 80, no seu $8^{\text {o }}$ Congresso, a ANAMPOS foi dissolvida, dando lugar à Comissão pró-Central de Movimentos Populares. Em outubro de 1993 foi realizado o Congresso de fundação da CMP, que tem como proposta a unificação dos diversos movimentos populares: movimentos de negros, mulheres, moradia, cultura, rádios comunitárias, indígenas, dentre outros ${ }^{7}$.

Essas quatro entidades têm assento no Conselho das Cidades e estão articuladas ao Fórum Nacional de Reforma Urbana (FNRU), que existe desde 1987 e está organizado em todas as regiões do Brasil.

O FNRU surgiu do Movimento Nacional de Reforma Urbana (MNRU), que se constituía numa "ampla frente de mobilização no período da Assembleia Constituinte" (BRASIL, 2011, P. 4).

De acordo com a pesquisadora Flávia Brasil (2011), tanto o MNRU quanto o FNRU não chegaram a se institucionalizar como organizações formais. Entretanto, mesmo preservando traços informais, esses atores coletivos (em especial o FNRU) apresentam uma grande longevidade e uma ampla capacidade de mobilização e de influência, tanto nos processos decisórios quanto no marco legal das políticas urbanas brasileiras.

O FNRU se fundamenta a partir de três princípios fundamentais.

$>\quad$ O primeiro deles é o Direito à Cidade, que se traduz em: direito à moradia digna, aos meios de subsistência, ao saneamento ambiental, à saúde, à educação, ao transporte público, à alimentação, ao trabalho, ao lazer e à informação.

O segundo princípio é o da Gestão Democrática das Cidades, ou seja, os cidadãos têm

${ }^{7}$ Mais informações ver: http://www.forumreformaurbana.org.br/. 
Participação popular e política habitacional em Belo Horizonte/MG

que participar das decisões fundamentais para o futuro das cidades.

$>\quad$ O terceiro princípio é o da Função Social da Cidade e da Propriedade, segundo o qual o espaço das cidades tem que servir, antes de tudo, aos interesses coletivos das grandes maiorias.

Os movimentos ligados à reforma urbana protagonizaram avanços que foram incorporados pelo Estado. Entre esses avanços pode-se destacar:

1. A inclusão do direito à moradia como um direito social fundamental na Constituição Federal de 1988;

2. A aprovação do Estatuto da Cidade em 2001;

3. A criação do Ministério das Cidades, cuja engenharia institucional abre espaço para participação da sociedade civil a partir da Conferência Nacional das Cidades (CNC) e do Conselho das Cidades (Concidades);

4. A instituição do Sistema Nacional de Habitação de Interesse Social e do Fundo Nacional de Habitação de Interesse Social.

\section{Participação Popular e Política Habitacional em Belo Horizonte}

Belo Horizonte foi inaugurada no dia 12 de dezembro de 1897 como uma cidade que representava os novos tempos da república, pois era o fruto de um planejamento técnico simbolizando a ordem e o progresso. De acordo com João Antônio de Paula e Roberto Luís de Melo Monte-Mor:

A construção de Belo Horizonte é o resultado de uma conciliação que realiza a aglutinação de monarquistas liberais e dos republicanos, que terá como resultado político maior numa hipostasia: a apresentação da nova capital mineira, seu traçado geométrico sua modernidade arquitetônica, como o máximo do projeto republicano (PAULA; MONTEMOR, 2001, p. 30). 
Todavia, Belo Horizonte é uma cidade que nasceu marcada por um profundo dualismo: de um lado encontra-se a "cidade formal", pensada e planejada dentro da racionalidade científica que marcou o século XIX'; de outro, a "cidade informal", que extrapolou o que tinha sido planejado.

A cidade foi planejada rigidamente do ponto de vista da engenharia e do urbanismo vigentes na época da sua construção (entre 1893 e 1897), com a angulação precisa das ruas, a disposição simétrica dos quarteirões e uma separação e organização do espaço urbano. Todavia, essa organização desconsiderou totalmente os aspectos sociais. O projeto da nova capital ignorou a organização social existente anteriormente e não previu espaço para os trabalhadores que iriam construí-la. Sendo assim, as primeiras favelas surgiram enquanto a cidade ainda estava em construção e os trabalhadores, como não tinham moradia, se instalaram nas proximidades das obras. A cidade estava sendo construída para uma população constituída basicamente de funcionários públicos, proprietários e comerciantes da antiga capital do estado9. Os trabalhadores eram vistos como uma população temporária.

De acordo com Afonso e Azevedo (1988), a nova capital de Minas Gerais, em seus primeiros anos, defrontava-se com o seguinte problema: por um lado, uma zona urbana dotada, em parte, de infraestrutura, mas esvaziada ${ }^{10}$, isto é, um plano urbanístico desprovido de cidade; por outro as zonas suburbana e rural muito povoadas, mas carecendo de serviços básicos e demandando-os da prefeitura. A ocupação da nova capital se deu da periferia para o centro.

De acordo com Berenice Martins Guimarães (1992), quando o projeto da nova capital começou a se tornar realidade, o poder público começa a regulamentar a situação das invasões visando retirar a população pobre da parte nobre da cidade ${ }^{11}$. Nesse sentido, a prefeitura designou um

\footnotetext{
${ }^{8} \mathrm{O}$ engenheiro encarregado do projeto e da obra da nova capital, Aarão Reis, era um homem de profunda convicção positivista.

${ }^{9}$ Isso não significa que Belo Horizonte foi criada para ser uma cidade de funcionários públicos. Desde o início havia a intenção de industrializá-la, mas devido a vários fatores esse processo começou apenas na década de 1940. ${ }^{10}$ Devido ao alto valor dos terrenos e as exigências urbanísticas.

${ }^{11} \mathrm{O}$ surgimento das favelas nas áreas nobres da cidade se deu devido aos vazios que lá se encontravam. Os altos preços dos terrenos no centro empurravam a
} 
Participação popular e política habitacional em Belo Horizonte/MG

local para moradia dos trabalhadores e promoveu a primeira remoção de favelas em 1902. A nova capital nasceu com um caráter claramente segregacionista: as elites políticas e econômicas no centro da cidade; e a população pobre na periferia ocupada desordenadamente. Segundo Afonso e Azevedo (1988)

Paralelamente ao desfavelamento, o poder público começou a se preocupar com a localização das camadas de baixa renda, destinando, às mesmas, áreas especiais fora do centro urbano. Exemplo disso é o Decreto 1.516, de 2 de maio de 1902, que destinava a $8^{\circ}$ seção urbana (atual Barro Preto) para a construção da primeira vila Operária da Capital (AFONSO; AZEVEDO, 1988, p. 113).

Todavia, mesmo essa área designada para os trabalhadores rapidamente tornou-se incapaz de absorver o constante fluxo de população, muito em razão da especulação imobiliária que sempre caracterizou Belo Horizonte. Sendo assim, estabeleceu-se a seguinte dinâmica entre o poder público e a população pobre da cidade: os trabalhadores eram obrigados a ocupar as áreas mais desvalorizadas ou áreas onde a mão-de-obra era necessária, até o momento em que seriam retirados pela prefeitura quando o crescimento da cidade tornava valorizada aquela área.

Todas as favelas que existiam na parte nobre da cidade foram removidas e a população expulsa para locais mais distantes. Com o tempo, até as favelas mais distantes passaram a ser alvo de remoções, com o argumento de que seriam realizadas obras de natureza urbanística e de saneamento básico. Começa-se a desenvolver a imagem de que essas áreas seriam foco de epidemias e de criminalidade. Muitas vezes, a população removida voltava a ocupar a mesma área como estratégia de resistência. Para Berenice Martins Guimarães, essa foi a dinâmica da cidade nos seus primeiros 30 anos.

Até o fim da República Velha, o tratamento das áreas de favelas era quase puramente repressivo. Merecem destaque, no entanto, as primeiras tentativas de organização da população periférica, que ocorreram ao longo

população para a periferia desprovida de bens públicos. Parte da população pobre resolveu esse impasse ocupando áreas vazias dentro da cidade formal. 
da década de 1930, inclusive com tentativas de disciplinar o mercado imobiliário em Belo Horizonte.

Com a implantação do Estado $\mathrm{Novo}^{12}$, no qual vigorou o pacto populista, o estado passou a responder a algumas demandas das camadas populares, porém o fez mantendo o controle sobre as manifestações populares que, segundo Afonso e Azevedo (1988), foram completamente desmobilizadas. O estado populista concentrou esforços na regulação das relações de trabalho, não respondendo às necessidades de infraestrutura urbana na periferia, o que só agravou o problema. Além disso, a política do desfavelamento continuou.

O problema das favelas em Belo Horizonte agravou-se a partir das décadas de 1940 e 1950, devido ao processo de industrialização pelo qual passou o Brasil. Dessa forma, intensificou-se o fluxo migratório para as cidades do sudeste, Belo Horizonte entre elas, com isso o centro urbano da capital foi sendo ocupado em um ritmo superior à oferta de infraestrutura. Se na cidade formal a situação se deteriorou rapidamente, nas áreas favelizadas a situação era caótica, e ainda com um agravante: a questão das áreas pobres da cidade era tratada como um problema policial. A solução para as favelas continuava sendo sua erradicação. Apesar de ainda existir muita repressão, nesse período a população pobre de Belo Horizonte conseguiu abrir espaço para suas reivindicações através das Associações de Defesa Coletiva (ADC). Também multiplicaram-se as organizações populares que contavam com o apoio de setores progressistas da Igreja Católica. Em Belo Horizonte, esses movimentos fortaleceram-se tanto que conseguiram eleger um candidato ${ }^{13}$ à prefeitura comprometido com os problemas das favelas.

Essa nova administração criou, em 1955, o Departamento Municipal de Habitação e Bairros Populares (DBP), com o objetivo de construir habitações populares a baixo custo, destinadas prioritariamente a atender a população favelada do município. Mas a política das remoções continuava sendo o carro chefe.

Na década de 1960 houve intensa movimentação da população favelada de Belo Horizonte, muitas passeatas e invasões de terrenos. Esses movimentos contavam com o apoio de políticos de esquerda e de alguns setores da Igreja Católica. Em 1963 o governo do Estado de Minas Gerais,

12 Período entre 1937 e 1945.

${ }^{13} \mathrm{O}$ candidato era o empresário da construção civil chamado Celso Melo Azevedo. 
Participação popular e política habitacional em Belo Horizonte/MG

em resposta às reivindicações do movimento dos favelados, propôs a construção de conjuntos habitacionais, bem como a urbanização de algumas favelas em Belo Horizonte.

Contudo, com o golpe militar de 1964, todas as iniciativas para melhorias nas favelas retrocederam, voltaram a ser objeto de ação policial e as associações de favelas foram declaradas subversivas. Segundo Afonso e Azevedo:

Em dezembro de 1965 foi criado um órgão de assessoria ao DBP, os Serviços Municipais para Desfavelamento das Áreas Urbanas e Suburbanas, que em três meses de existência derrubou mais barracões que o DBP fizera em 10 anos de existência (AFONSO; AZEVEDO, 1988, p. 119).

A única forma de resistir ao desfavelamento era a via jurídica, que contava com o apoio do Departamento de Assistência Jurídica da Faculdade de Direito da UFMG. Em 1971, a DBP foi substituída pela Coordenação de Habitação de Interesse Social de Belo Horizonte (CHISBEL): um órgão voltado exclusivamente para o desfavelamento. Em 12 anos a CHISBEL removeu 10 mil barracos em diversas áreas da cidade. As remoções eram feitas mediante indenizações que, via de regra, eram insuficientes para a aquisição de um terreno, obrigando a população a formar novas favelas em locais mais distantes.

Já em um contexto de crise do "Milagre Brasileiro", somado ao aumento das pressões populares em decorrência das grandes enchentes de 1979 e 1982, os problemas de infraestrutura urbana das favelas voltaram a ganhar visibilidade. Do ponto de vista organizativo, em meados de 1974 surge a Pastoral das Favelas que buscava congregar os diversos grupos ligados ao movimento dos favelados ${ }^{14}$. Também merece destaque a ação da União dos Trabalhadores Favelados - UTP.

No período de redemocratização, os movimentos dos favelados se fortalecem e o estado começa a reconhecer o direito da população permanecer na área ocupada. Um exemplo disso é a criação do Programa

${ }_{14}$ Umas das figuras centrais da Pastoral da Favela foi o Padre Piggi, ainda hoje muito atuante na região norte da cidade. 
de Desenvolvimento de Comunidades ${ }^{15}$ (PRODECOM) do governo estadual. Gradativamente, a favela deixou de ser considerada como um fenômeno provisório e começou a ser reconhecida como parte do próprio processo de urbanização desenfreada das grandes cidades, começando a surgir discussões e propostas de se enfrentar esse problema a partir da permanência dessas populações nos seus locais de moradia, com a urbanização das respectivas áreas. Nessa nova abordagem, o conceito de urbanização é ampliado, abrangendo a implantação de infraestrutura urbana completa (postos de saúde, escolas, creches, regularização fundiária).

O ano de 1983 também foi um marco para a questão das favelas em Belo Horizonte pois, nesse ano, a Câmara dos Vereadores aprovou o Programa Municipal de Regularização de Favelas (PRÓ-FAVELA), que representou "um instrumento através do qual o poder público reconhecia de forma explícita, o direito do favelado a propriedade de sua moradia" (GUIMARÃES, 1992, p. 15). A lei foi aprovada rapidamente, mas sua regulamentação se arrastou por quase dois anos, exigindo muito esforço dos movimentos populares interessados na questão.

Para implementar o PRÓ-FAVELA, foi criada a Companhia Urbanizadora de Belo Horizonte (URBEL), que passou a ser o órgão responsável pelas questões relacionadas à habitação popular e às favelas: construção de unidades habitacionais, urbanização, regularização e até mesmo a remoção nos casos em que for necessário.

Todo esse processo que culminou na criação da URBEL fez com que as vilas e favelas deixassem de ser consideradas como "desvios urbanísticos", passando a ser tratadas como parte integrante da cidade. A questão habitacional passa a ser encarada como algo mais abrangente que a simples moradia, incluindo também acesso aos serviços públicos ${ }^{16}$. Essa

15 O PRODECOM representou um marco na política voltada para as favelas promovendo a urbanização das áreas com a legalização da posse e a participação das comunidades ali residentes.

${ }_{16}$ Dentro desse entendimento, a prefeitura passa a desenvolver planejamentos integrados (chamados de Planos Globais Específicos) envolvendo as questões físicas (saneamento, urbanismo, geologia, etc.), sociais (acesso aos serviços público de educação, saúde, assistência social, segurança; inserção no mercado de trabalho; associativismo) e jurídicas (situação da posse fundiária com vistas à regularização da posse). 
Participação popular e política habitacional em Belo Horizonte/MG

nova concepção vem acompanhada da convicção de que a participação dos moradores é uma condição sine qua nom para o desenvolvimento de políticas urbanas eficazes.

Todavia, apesar de todo esse histórico, a emergência de uma política municipal de habitação só passa a ser possível após a falência do Sistema Habitacional erguido durante o período militar. A extinção do $\mathrm{BNH}$ representou o fim de uma concepção de intervenção estatal centralizada, fazendo com que as instâncias subnacionais implementassem políticas locais, a partir de um processo que pode ser chamado de descentralização por ausência ${ }^{17}$ (ARRETCHE, 2000).

Dentro do grande movimento de descentralização nas décadas de 80 e 90, a Política Municipal de Habitação do município de Belo Horizonte surge em 1994, inaugurando "mecanismos e instrumentos de participação direta da população organizada no processo de tomada de decisão" (RIBEIRO, 2001, p. 13).

A Política Municipal de Habitação de Belo Horizonte foi gestada durante a administração da Frente BH Popular (1993 - 1996), cujo prefeito era o Sr. Patrus Ananias, do Partido dos Trabalhadores (PT). A partir desse momento, a participação popular foi incorporada na gestão da cidade através de diversos mecanismos, em especial o Orçamento Participativo $(\mathrm{OP})$, o Orçamento Participativo da Habitação (OPH), O Conselho Municipal de Habitação (CMH), o Fundo Municipal de Habitação Popular (FMHP) e as Conferências Municipais de Habitação.

Entre os princípios basilares da política estavam a vinculação da política habitacional com a política urbana e a gestão democrática, assegurada por canais formais de participação da população organizada, em todas as etapas do empreendimento.

No que tange o gerenciamento dos empreendimentos, as formas elencadas foram a gestão pública, a co-gestão e a autogestão. Salienta-se que esta última era vista como a forma preferencial, em função de apresentar um custo mais baixo e viabilizar uma real participação popular em todas as etapas do empreendimento, auxiliando no "crescimento social e político dos indivíduos e grupos sociais enquanto cidadãos no exercício e conquista de seus direitos"' (RIBEIRO, 2001, p. 49).

17 Forçar a elevação da participação dos níveis subnacionais pela ausência de recursos do governo federal. 
No que se refere à produção habitacional, a orientação da política é priorizar as demandas coletivas organizadas em movimentos de luta pela moradia. Além de estarem associadas ao Movimento de Luta por Moradia, como condição para serem beneficiadas por unidades habitacionais produzidas pela política municipal, as famílias deveriam se enquadrar em outros critérios: possuir renda de até 5 salários mínimos, residir no município há mais de 2 anos e não terem sido beneficiadas anteriormente pela política.

A figura abaixo mostra a configuração atual da Política Municipal de Habitação, com todos os programas e instrumentos de planejamento que a compõem. Ressaltando que não é objetivo deste artigo entrar nos detalhes de todos os pontos da política.

FIGURA 1 - Principais Programas da Política Municipal de Habitação do Município de Belo Horizonte

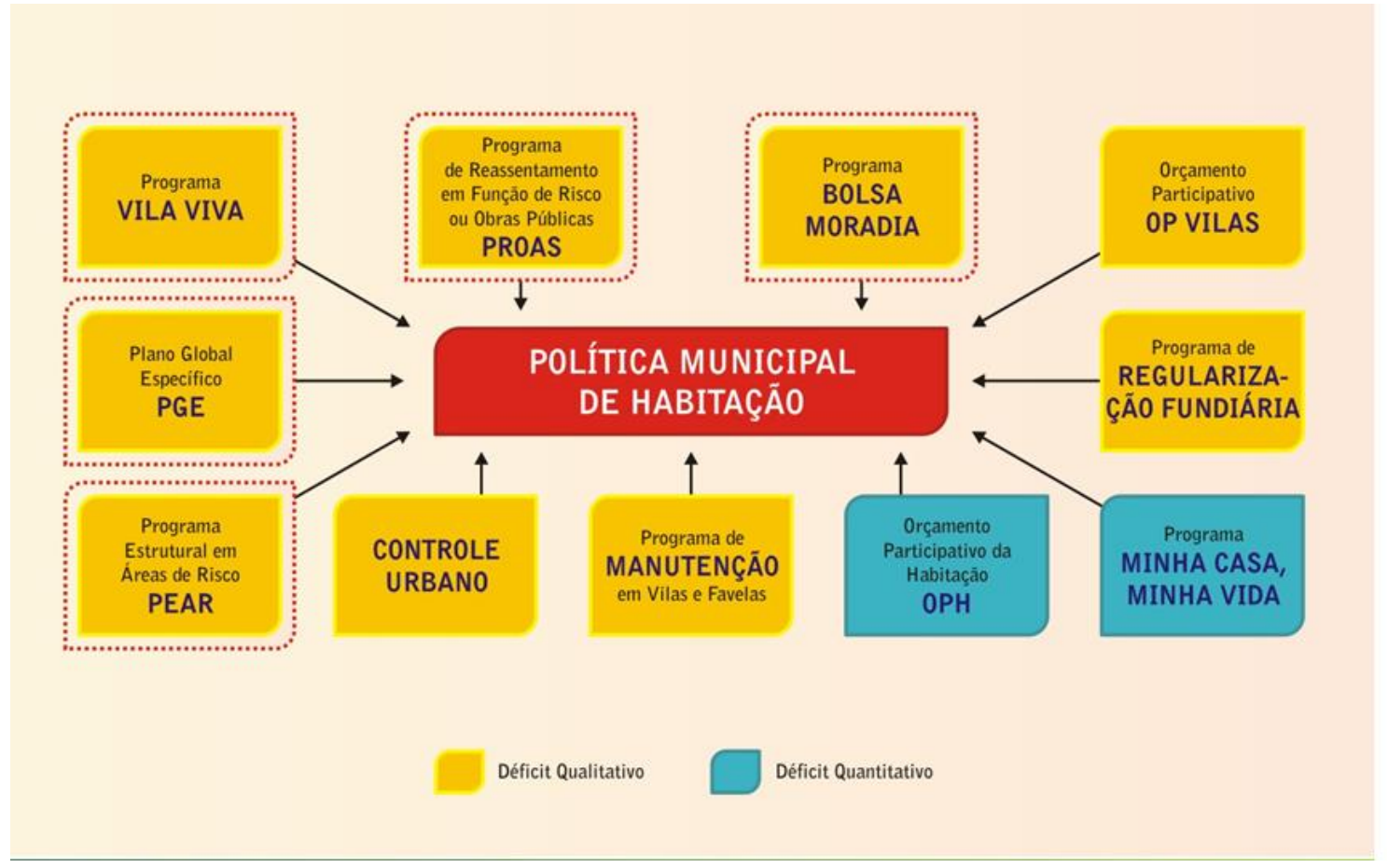

Fonte: Prefeitura Municipal de Belo Horizonte (2013).

Enfatizando a questão da produção habitacional, o Orçamento Participativo da Habitação surgiu dentro dos processos de discussão do OP 
Participação popular e política habitacional em Belo Horizonte/MG

de 1995. No início da década de 1990, o movimento de luta por moradia demostrava uma grande capacidade de mobilização, contando com o apoio da Igreja Católica ${ }^{18}$ e utilizando a estratégia da ocupação de terrenos como forma de pressão. As lideranças do movimento reconheceram no OP uma oportunidade para disputar e ganhar recursos para produção de moradias. Essa estratégia colocava o poder público municipal diante de dois dilemas: primeiro, os recursos destinados para o OP não comportariam a demanda do movimento de luta por moradia. Além disso, corria-se o risco de concentrar recursos na produção habitacional, em função da grande capacidade de mobilização do movimento, em detrimento das obras de infraestrutura.

O segundo dilema, ainda mais complexo, dizia respeito à natureza dos bens produzidos. O OP teria como objetivo definir prioridades orçamentárias visando atender o maior número possível de pessoas; entretanto, as unidades habitacionais são bens de apropriação individual. Sendo assim, surgiu o debate: "como conjugar numa mesma arena de discussão e deliberação pública a destinação de recursos para bens de natureza coletiva e aqueles apropriados de forma particular?" (MELO, 2008, p. 49).

Após um amplo debate dentro do Conselho Municipal de Habitação, decidiu-se por instituir um Orçamento Participativo exclusivo para produção habitacional, com dotação orçamentária própria (RIBEIRO, 2001).

A instituição do $\mathrm{OPH}$ em Belo Horizonte está associada à grande capacidade de mobilização e pressão do movimento popular de luta por moradia. O OPH é o reconhecimento formal, por parte do poder público municipal, da legitimidade e da força organizativa do movimento.

Em termos da dinâmica de funcionamento, o OPH destinava "um montante de recurso a ser disputado por todos os grupos de sem-casas devidamente inscritos e que participavam efetivamente de todas as etapas que envolvem o processo de discussão e aprovação pública" (MELO, 2008, p. 51).

O Programa sofreu diversas alterações ao longo de sua existência, mas, de maneira geral, seguia os seguintes trâmites.

${ }^{18}$ No ano de 1993 a Campanha da Fraternidade teve como mote o lema "Onde Moras?" 
1. A Secretaria de Planejamento define o montante de recursos para cada edição do $\mathrm{OPH}$;

2. O Conselho Municipal delibera sobre a distribuição dos recursos, forma de gestão e calendário para realização das plenárias regionais e do Fórum de Habitação;

3. Credenciamento dos núcleos de luta por moradia que apresentam a relação de associados neles inscritos;

4. Assembleias regionais para apresentar as deliberações do Conselho Municipal de Habitação (volume de recursos, sua forma de distribuição, etc.), balanço da Política Habitacional do município e eleição dos delegados para o Fórum de Habitação (o número de delegados de cada núcleo é calculado de acordo com o número de associados apresentados no ato da inscrição. Após 1998 a presença nas assembleias também passou a ser um critério);

5. No Fórum da Habitação, os delegados definem os critérios e normas para distribuição dos recursos e elegem os membros da COMFORÇA ${ }^{19}$ de Habitação, que terá a atribuição de fiscalizar a aplicação do recurso.

Os núcleos de luta por moradia ainda detinham a "prerrogativa de escolher, dentre os seus associados, aqueles que preencherão as vagas conquistadas na discussão pública do OPH" (MELO, 2008, p. 52). Sendo assim, os núcleos eram uma instância fundamental dentro da política habitacional de Belo Horizonte, gozando de grande autonomia com relação ao estabelecimento dos critérios de distribuição das unidades.

Essa autonomia dos núcleos gerou diversas denuncias sobre a falta de critérios claros para a definição das famílias a serem beneficiadas ${ }^{20}$.

19 Comissão de Acompanhamento e Fiscalização da Execução do Orçamento Participativo.

20 De acordo com Antônio Melo foram recorrentes denúncias de escolhas ilegítimas envolvendo: favorecimento de familiares, comercialização de vagas, 
Participação popular e política habitacional em Belo Horizonte/MG

Tanto que foi necessária a criação de uma Comissão de Ética cuja função é averiguar os casos de denúncias e, quando pertinentes, leva-los ao conhecimento da COMFORÇA e do Conselho Municipal de Habitação.

Segundo Frank Ribeiro (2001), as relações horizontais estabelecidas pela Política Municipal de Habitação de Belo Horizonte contrastam com as relações verticais, baseadas em valores políticos tradicionais, que se estabeleceram nas dinâmicas internas de alguns núcleos.

A autonomia e a independência dos núcleos no processo de distribuição das unidades habitacionais proporcionaram situações de mandonismo, por parte de alguns coordenadores, que se configuraram, nas palavras de Frank Ribeiro (2001), em uma situação de "neoclientelismo urbano".

A intensão deste trabalho não é fazer uma análise minuciosa do Orçamento Participativo da Habitação ${ }^{21}$, mas apenas contextualizar os conflitos e contradições de um experimento participativo aos moldes do que foi gestado na política habitacional do município de Belo Horizonte.

\section{Considerações Finais}

A ideia de implementar, planejar ou fiscalizar uma política com a participação da sociedade apresenta muitas dificuldades e desafios. Muitas vezes essa participação não é decorrente de uma consciência cívica, organizada espontaneamente para defender os interesses da coletividade. O que se percebe em alguns casos é a participação como fruto de uma exigência da legislação. Nesse caso, a capacidade do Estado para induzir ou potencializar a participação ou o associativismo civil é uma premissa polêmica.

Um "simples" arranjo institucional não pode sozinho "criar" a participação. Eventualmente, as instituições podem potencializar certos traços da cultura política participativa onde ela já existia. Tradições prévias de associação afetam profundamente a eficiência dos arranjos institucionais participativos.

Essa foi a grande conclusão a que chegou Robert Putnam (1996) em seu famoso livro "Comunidade e Democracia a experiência da Itália moderna". Segundo o autor, reformas institucionais nem sempre alteram

favores sexuais, falsificação de atas de indicação de associados e processos de indicação sem a realização de assembleias (MELO, 2008, P. 53).

21 Para maiores detalhes sobre o OPH ver RIBEIRO (2001) e MELO (2008). 
padrões fundamentais da política. Para Putnam, a eficácia de uma instituição é profundamente afetada pelo contexto social, que por sua vez é construído historicamente.

Em outras palavras, a eficiência de arranjos participativos dependeria do capital social da comunidade. Importante destacar que Putnam entende que capital social ${ }^{22}$ "diz respeito a características da organização social como confiança, normas e sistemas, que contribuam para aumentar a eficiência da sociedade, facilitando as ações coordenadas" (PUTNAM, 1996, p. 177).

Putnam acredita que:

Uma característica específica do capital social confiança, normas e cadeias de relações sociais - é o fato de que ele normalmente constitui um bem público, ao contrário do capital convencional, que normalmente é um bem privado. Por ser um atributo da estrutura social em que se insere o indivíduo, o capital social não é propriedade particular de nenhuma das pessoas que dele se beneficiam (PUTNAM, 1996, p. 180).

Segundo Putnam, o sucesso de políticas públicas, de governos, e até mesmo da economia, pode ser largamente explicado pela progressiva acumulação de capital social. E, para ele, a forma essencial de capital social são os sistemas de participação cívica (associações comunitárias, partidos, sindicatos, clubes desportivos etc.). Se uma sociedade é forte, o Estado e a economia também serão fortes.

Essa concepção apresenta três problemas:

A primeira é que ela parece insinuar que, "ao se chegar ao ponto em que um alto índice de capital social é encontrado, chega-se à fórmula para a resolução de todos os problemas" (CIRENO, 2005, p. 76);

Segundo, o argumento cai em uma tautologia: as instituições são eficientes devido ao alto estoque

${ }^{22}$ Uma discussão mais detalhada sobre o conceito de capital social pode ser encontrada em PORTES (1998) SANTOS (2006), COLEMAN (1988), CIRENO (2005), HIGGINS (2012). 
Participação popular e política habitacional em Belo Horizonte/MG

de capital social; e esse estoque continua alto devido à eficiência das instituições;

Por último, ela parece fazer uma condenação eterna aos países com baixo capital social, estabelecendo um círculo vicioso no qual: o baixo estoque de tradição cívica implicaria no fracasso das políticas públicas, governos e economia e o fracasso dessas dimensões dificultaria a constituição ou fortalecimento da tradição cívica.

Tendo em vista esses problemas mencionados acima e contrapondose à condenação implícita, contida no argumento de Putnam (1996), Peter Evans entende que os arranjos participativos não devem ser desconsiderados pelo fato de terem sido criados de cima para baixo e não terem ainda um "lastro" social. As instituições participativas têm uma grande importância, pois elas podem, de alguma forma, "favorecer" a participação. Para haver uma sinergia entre Estado e sociedade civil, a existência de arranjos institucionais permeáveis à participação são de fato um componente importante, juntamente com níveis prévios de organização societária.

Em um primeiro momento, o arranjo institucional sozinho não é capaz de inaugurar um novo estilo de relação entre Estado e Sociedade, moldando o comportamento dos atores sociais (no caso, criando participação). A decisão de participar ou não depende da interação de uma série de fatores sociais, institucionais e individuais (como escolaridade e acesso à informação). Mas, sem dúvida alguma, o fato do Estado estar aberto à participação já é um ponto positivo, pois pode criar condições para que, com o passar do tempo, haja um maior enraizamento de formas de organização popular.

Se, por outro lado, entendermos o conceito de capital social com um viés mais instrumental, como um elemento estratégico para os indivíduos, como fizeram Coleman e Bourdieu, também estar-se-ia perdendo uma dimensão crucial: os problemas relacionados à ação coletiva (HIGGINS, 2012). Sendo assim, o capital social entendido como um recurso individual não contribui para trabalharmos o fenômeno da sinergia.

Tendo em vista o objetivo deste trabalho, analisar a interação entre Estado e sociedade civil dentro da política habitacional, a melhor forma de operacionalizar o conceito de capital social é entendê-lo através das redes 
sociais. Entender o capital social como as ligações entre as pessoas deixando de lado uma concepção mais estanque baseada na coesão (HIGGINS, 2012). Nessa perspectiva, um aparato estatal que mantenha uma densa teia de vínculos com grupos sociais diversos abre a possibilidade de criação e manutenção de uma sinergia.

Lembrando que, segundo Peter Evans (2004), esses vínculos societários devem vir acompanhados de "uma burocracia capacitada, de seleção meritocrática e que siga carreiras que ofereçam retornos de longo prazo comparáveis àqueles oferecidos pelo setor privado" (EVANS, 2004, p. 10). Isso geraria a autonomia fundamental para que os interesses particulares não subvertam os objetivos gerais.

A conjunção de autonomia e parceria é fundamental, pois como salientou Peter Evans:

Tanto a autonomia quanto a parceria podem isoladamente produzir resultados perversos. Sem autonomia, a distinção entre parceria e captura do Estado desaparece. A autonomia sozinha não significa necessariamente um interesse no desenvolvimento, tanto no sentido estreito de crescimento econômico quanto no sentido mais amplo de melhoria do bem-estar. O segredo do Estado desenvolvimentista se encontra no amálgama destas duas dimensões (EVANS, 2004, p. 93).

No caso da política habitacional, a própria natureza do bem em jogo (a moradia) e suas características (uma necessidade universal, cara e de apropriação individual) fornecem um substrato propício à participação social. O movimento popular por moradia teve, ao longo dos anos, uma trajetória consistente obtendo diversas conquistas, principalmente após 2003, com a criação do Ministério das Cidades e a instituição de instâncias tais como o Sistema Nacional de Habitação de Interesse Social, o Plano Nacional de Habitação e o Conselho das Cidades que favoreceram a sinergia entre sociedade civil e poder público.

O caso da Política habitacional, especificamente o tipo de política que se desenvolveu no município de Belo Horizonte, a partir de 1993, e no Governo Federal, a partir de 2003, é um excelente exemplo de como o 
Participação popular e política habitacional em Belo Horizonte/MG

Estado pode transformar sua relação com a sociedade, trazendo novos atores para o palco social. Todavia, uma vez lá, esses atores desenvolvem suas próprias agendas, reformulando o processo de participação levando a resultados inesperados e, por vezes, indesejados.

\section{Referências Bibliográficas}

AFONSO, Mariza Rezende; AZEVEDO, S. Favela, Cidade e Poder Público. In: POMPERMAYER, Malori (org.) Movimentos Sociais em Minas Gerais. Belo Horizonte, Editora da UFMG, 1988.

ARRETCHE, Marta T. S. Estado federativo e politicas sociais: determinantes da descentralização. Rio de Janeiro: Revan; São Paulo: FAPESP, 2000.

AVRITZER, Leonardo. Sociedade Civil e Participação Social no Brasil (2000). Disponível em : www.democraciaparticipativa.org.

BEDÊ, Mônica Maria Cadaval. Trajetória da formulação e implantação da política habitacional de Belo Horizonte na gestão da Frente $\mathrm{BH}$ Popular: 1993 / 1996. 2005. 302 f. Dissertação (mestrado) - Universidade Federal de Minas Gerais, Departamento de Geografia, Belo Horizonte, 2005.

BRASIL, Flávia de Paula Duque. Democracia e Participação Social: A Construção de Avanços Democratizantes nas Políticas Urbanas Pós-1980. 2011. 251 f. Tese (Doutorado em Sociologia) - Faculdade de Filosofia e Ciências Humanas, Universidade Federal de Minas Gerais, Belo Horizonte, 2011.

CARNEIRO, Ricardo; SOUZA, José Moreira. Moradia popular e política pública na região metropolitana de Belo Horizonte: revisitando a questão do déficit habitacional. in: FAHEL, Murilo; NEVES, Jorge Alexandre Barbosa. (org.). Gestão e Avaliação de Políticas Sociais no Brasil. 01 ed. Belo Horizonte-MG: editora PUCMINAS, 2007, v. 01, p. 29-49. 
CARNEIRO, R.; SOUZA, J. M.; BRASIL, F. P. D.; BARBOSA, T. P. . Habitação de interesse social: considerações a partir da experiência de Belo Horizonte. Revista Avaliação de Políticas Públicas, v. 1, p. 7-16, 2010.

CIRENO, Flávio. Evidências do efeito do capital social e do capital humano sobre a empregabilidade e a renda no PEQ 2001 em Pernambuco. In: IV Fórum de Desenvolvimento: Capital Social diferentes visões. Recife UFPE, 2005. CD-ROM.

COLEMAN, James. Social Capital in the Creation of Human Capital. American Journal of Sociology, Chicago IL, v. 94. Supplement: Organizations and institutions: sociological and economic approaches to the analysis of social structures p. 95-120. The University of Chicago press, 1988.

DAMATTA, Roberto. A casa \& a rua: espaço, cidadania, mulher e morte no Brasil. São Paulo: Brasiliense, 1985.

DOIMO, Ana Maria. A vez e a voz do popular: movimentos sociais e participação politica no Brasil pos-70. Rio de Janeiro: Relumé Dumará: Anpocs, 1995. 353p.

EVANS, Peter B. Autonomia e parceria: estados e transformação industrial. Rio de Janeiro: Ed. da UFRJ, 2004.

GUIMARÃES, Berenice Martins. Favelas em Belo Horizonte: tendências e desafios. Análise e Conjuntura. Belo Horizonte, v. 7, n. 2 e 3, p. 11-18, mai./dez. 1992.

HIGGINS, Silvio Segundo Salej. A difícil construção do capital social: estruturas da ação coletiva numa organização camponesa colombiana. Latin American Research Review, 2012, no prelo.

LEAL, Victor Nunes. Coronelismo, enxada e voto: o municipio e o regime representativo no Brasil. 2. ed. São Paulo: Alfa-Omega, 1975. 270p.

MELO, Antônio de Pádua Silveira de. Participação, Cultura Política e Racionalidade: A influência da natureza dos bens produzidos pelo 
Participação popular e política habitacional em Belo Horizonte/MG

Orçamento Participativo e Orçamento Participativo da Habitação sobre o processo de ação coletiva dos grupos de sem-casas e associações de bairros e favelas de Belo Horizonte. 2008. 273 f. Dissertação (Mestrado em Sociologia) - Faculdade de Filosofia e Ciências Humanas, Universidade Federal de Minas Gerais, Belo Horizonte, 2008.

NEVES, J. A. B.; HELAL, Diogo Henrique. Como Pode ter Dado Certo? Insulamento burocrático, inserção social e políticas públicas no Brasil: $\mathrm{O}$ caso do programa Bolsa Família. in: FAHEL, Murilo Fahel; NEVES, Jorge Alexandre Barbosa (org.). Gestão e Avaliação de Políticas Sociais no Brasil. 01 ed. Belo Horizonte-MG: editora PUCMINAS, 2007, v. 01, p. 29-49.

PAULA, João Antônio de; MONTE-MOR, Roberto Luis de Melo. (2001). As Três Invenções de Belo Horizonte. In.: Anuário Estatístico de Belo Horizonte, 2001.

PORTES, Alejandro. Social Capital: Its Origins and Applications in Modern Sociology. Annual review of Sociology, 24 1-24, 1998.

PUTNAM, Robert. Comunidade e Democracia a experiência da Itália moderna. Editora Fundação Getúlio Vargas. Tradução Luiz Alberto Monjardim. Rio de Janeiro 1996.

RIBEIRO, Frank de Paula. Cidadania Possível ou Neoclientelismo Urbano? Cultura e Política no Orçamento Participativo da Habitação em Belo Horizonte (1995-2000). 2001. 176 f. Dissertação (Mestrado em Administração Pública) - Escola de Governo da Fundação João Pinheiro, Belo Horizonte, 2001.

SANTOS, Caroline. (2006). Capital Social e Capital Humano: subordinação ou independência? Uma análise a partir do estudo de caso nos Conselhos Municipais de Macaé e Resende. 118f. Dissertação de Mestrado em Economia. Universidade Federal Fluminense. Niterói. 2006.

SANTOS, Milton. A urbanização brasileira. 3. ed. São Paulo: Hucitec, 1996. 157p. ((Estudos urbanos;5)) ISBN 8527102307 (broch.) 
Davidson Afonso de Ramos

TOCQUEVILLE, Alexis de. A democracia na America.3. ed. Belo Horizonte, MG: Itatiaia, 1987. 597 p. (Biblioteca de cultura humanista; v.4). 